\title{
Saúde Mental, Gênero e Velhice na Instituição Geriátrica
}

\author{
Valeska Zanello ${ }^{1}$ \\ Lívia Campos e Silva \\ Guilherme Henderson \\ Universidade de Brasilia
}

\begin{abstract}
RESUMO - Este trabalho teve como escopo investigar como a velhice é vivenciada, de forma "gendrada", por homens e mulheres em uma instituição geriátrica e sua relação com a saúde mental. Foram realizadas 18 entrevistas, baseadas em um questionário semi-estruturado ( 9 com homens, 9 com mulheres). A análise das falas mostrou como as relações de gênero alicerçam as vivências das idosas e dos idosos institucionalizados, implicando em importantes diferenças e especificidades de sofrimento psíquico. Os resultados sugerem a importância de se levar em consideração os valores de gênero na formulação de políticas públicas de saúde mental para essa população.
\end{abstract}

Palavras-chave: saúde mental, velhice, relações de gênero, instituição

\section{Mental Health, Gender and Elderly in The Nursing Home}

\begin{abstract}
The scope of the present study is to investigate how aging is experienced in a gendered way, by men and women in a nursing home and its relation to mental health. 18 interviews, using a semi-structured questionnaire $(9$ with men, 9 with women) were performed. The analysis of the speeches showed how gender relations underpin the experiences of the institutionalized elderly (women and men), implying important differences and specificities of psychological distress. The results suggest the importance of taking into account the values of gender in the formulation of public policies on mental health for this population.
\end{abstract}

Keywords: mental health, elderly, gender relations

Nos últimos 50 anos houve um alargamento da expectativa de vida na população mundial, graças ao desenvolvimento do sistema de saneamento básico, bem como do sistema de saúde em geral. Isto proporcionou a possibilidade de envelhecimento a uma parcela cada vez maior da população, principalmente em países desenvolvidos e em desenvolvimento (Souza, 2006). De acordo com o último relatório do Fundo de População das Nações Unidas [UNFPA] em conjunto com a agência HelpAge International (2012) - "Envelhecimento no Século XXI: Celebração e Desafio"-, nos próximos dez anos, a quantidade da população idosa mundial será maior do que um bilhão de pessoas.

O envelhecimento populacional brasileiro é um fenômeno que não está desvinculado do cenário mundial. No Brasil, devido à diminuição da mortalidade infantil e ao declínio das taxas de natalidade, este fenômeno vem ocorrendo com uma significativa rapidez (Neri, 2004). Dados da ONU apontam que, entre 2012 e 2050, a proporção de idosos passará de $10 \%$ para $29 \%$ da nossa população; sendo que em 2025 , segundo a Organização Mundial de Saúde (OMS), o Brasil ocupará o $6^{\circ}$ lugar no ranking de países com maior número de idosos. Tendo esta perspectiva em vista, conhecer os vários aspectos biológicos, psicológicos e sociais que permeiam o envelhecimento faz-se fundamental, para que seja possível proporcionar serviços e concretizar políticas públicas efetivas

1 Endereço para correspondência: Departamento de Psicologia Clínica, Instituto de Psicologia, Universidade de Brasília, Campus Universitário Darcy Ribeiro, Asa Norte, Brasilia, DF, Brasil. CEP: 70910-900.

E-mail: valeskazanello@uol.com.br que promovam uma melhor qualidade de vida para essa faixa etária.

Um primeiro problema, no entanto, acerca da velhice diz respeito a sua definição, pois não há um consenso entre as áreas que a abordam. Três perspectivas se destacam na literatura científica sobre o tema: a médica-biológica, a sociológica/antropológica e a psicológica.

A perspectiva biológica promove a noção de velhice como uma perda gradual de funções corporais e a consequente maior susceptibilidade à contração de doenças. Ou seja, o foco é a degeneração do corpo biológico. Esta ideia tornou-se uma metáfora prevalente que se infiltrou no campo social, se fazendo viva ainda hoje. Foi a área multidisciplinar da gerontologia que disseminou uma série de práticas de prevenção, como cuidados à saúde, rejuvenescimento do corpo e desenvolvimento de uma vida social ativa, em clubes, universidades, atividades que construíram uma nova concepção da velhice como "Terceira Idade" (Moraes, 2011). Segundo Neri e Freire (2000), o termo "terceira idade" surgiu na França, na década de 60, com o objetivo de especificar a idade de aposentadoria das pessoas. Essa substituição se deu para que o termo "terceira idade" pudesse soar de forma mais agradável aos ouvidos dos idosos, e também dos não idosos, em relação ao termo "velhice" (Cachioni, 2003). O termo "terceira idade" disfarçaria, portanto, preconceitos, negando uma realidade comum a todos nós (Cachioni, 2003; Pereira, 2009).

De acordo com Lopes (2000), a ótica biológica não esgota a compreensão da velhice, pois, ao desconsiderar fatores psicológicos, sociais e culturais, este viés deixa de 
fora os sentidos sociais atribuídos às mudanças corporais relacionadas ao envelhecimento e o impacto psíquico destes sentidos nos sujeitos e suas formas de sofrer.

Assim, apesar de o envelhecimento geralmente ser percebido como um acontecimento homogêneo e estereotipado (universal), ele é um processo multifacetado e plural, pois além de ser marcado por mudanças corporais, implica em uma leitura social destas mudanças e atribuições de certos papéis sociais (ou perda/ausência deles). Segundo um viés sociológico/antropológico, a velhice deve ser compreendida a partir dos diversos contextos sociais, culturais e políticos em que ela se insere e através dos quais ela é interpretada. Assim, dentro de uma mesma sociedade como a nossa, encontramos no fenômeno do envelhecimento especificidades importantes no que tange a diferenças raciais, de gênero e de classe econômica que dão a este processo determinadas facetas. Faz-se mister pensar, portanto, a variabilidade do conceito de velhice em seu imbricamento com aspectos sociais que promovem uma vivência particular desta fase da vida. As representações sociais prevalentes da velhice em nossa cultura são, em geral, estigmatizantes, pois a reduzem a uma percepção estritamente relacionada à aparência corporal e à perda da juventude: um período fisicamente decadente. A pessoa idosa perde sua singularidade, dando lugar a uma corporeidade desfeita (Le Breton, 2011).

Já a Psicologia nem sempre teve o envelhecimento como objeto de estudo. Ao longo do século XX, o enfoque da Psicologia do Desenvolvimento se detinha aos estudos da infância e da adolescência. $\mathrm{O}$ processo de envelhecimento populacional ocorrido na Europa ocidental e nos Estados Unidos ao longo desse século acabou auxiliando o início de debates e pesquisas acerca do envelhecer, após os anos 50. A escassez de explicações satisfatórias para as fases posteriores à adolescência fez com que os pressupostos da Psicologia que não contemplavam a velhice caíssem por terra. Com o apoio das Ciências Sociais, a partir de seus entendimentos do sujeito humano como um ser histórico (Vieira, 2009), a Psicologia construiu meios de investigar os processos evolutivos na vida adulta e na velhice. Assim, abriu-se espaço para se pensar "envelhecimento e desenvolvimento como processos multidimensionais e multidirecionais" (Neri, 2004, p.70), a partir da consideração de influências de contextos culturais e sociais e das condições genético-biológicas e psicológicas (Neri, 2004).

Nesse sentido, a velhice pode ser definida na perspectiva da Psicologia do Envelhecimento como uma fase do desenvolvimento da vida que engloba um "delicado equilíbrio entre vantagens e limitações" (Neri, 2004, p.70). Ou seja, envelhecimento e desenvolvimento são eventos que estão correlacionados, e que são referentes a transformações comportamentais "descritas em termos de ganhos e de perdas" (Neri, 1995, p.29). A Psicologia do Envelhecimento tem, portanto, interesse tanto pelas transformações dos desempenhos cognitivos, afetivos e sociais, quanto por alterações motivacionais, de valores e atitudes que atravessam os anos tardios de vida (Neri, 1995; Neri, 2004). Seu foco são os fatores subjetivos desta fase, de modo que sejam conciliados aspectos do desenvolvimento e do envelhecimento, comumente contrapostos (Vieira, Miranda \& Coutinho, 2012).
Dois aspectos também se destacam no olhar psicológico sobre a velhice: o luto e as relações familiares. As mudanças recorrentes em várias instâncias da vida dos idosos trazem consigo o luto, o qual pode ser potencializado pelo contexto em que o idoso se insere, sobretudo as relações familiares e a convivência social. A partir dos elos e vínculos formados, a família pode atuar como uma fonte de amparo, tendo, potencialmente, primazia no suporte dado às pessoas idosas, em nossa cultura (Carvalho, 2009). Modo de elaboração dos lutos relativos ao próprio envelhecer e suporte social se refletem no bem-estar e no grau de satisfação dos idosos nas múltiplas vivências da velhice. A psicologia do envelhecimento enfatiza assim a necessidade de se pensar a possibilidade da existência de modelos de envelhecimento e velhice e de pessoas idosas que também se mantém saudáveis (Falcão \& Carvalho, 2010).

O gênero parece ser um fator importante neste processo. Dados no Brasil, como no mundo em geral, apontam para uma diferença de durabilidade desta fase da vida entre homens e mulheres, havendo um predomínio da população de mulheres idosas denominado feminização da velhice (Carvalho \& Garcia, 2003; Fernandes, 2009). Segundo Campos (2005), os fatores geradores desse fenômeno podem estar relacionados a diferenças de gênero no que tange à exposição a riscos no trabalho e a mortes por acidentes (quatro vezes mais frequentes em homens) e ao consumo de drogas lícitas e ilícitas que levam à morte por meio de doenças cardiovasculares (mais comuns em homens acima de 45 anos). Além disso, as mulheres parecem ser culturalmente mais cuidadosas em relação à própria saúde (Gonçalves, 2001).

Apesar deste processo de feminização da velhice e do aumento da população idosa no Brasil e no mundo, pouco se sabe sobre a prevalência epidemiológica dos transtornos mentais entre os idosos levando em conta sua frequência distinta entre os gêneros (Angold \& Heim, 2008). Este é um campo incipiente, para o qual a Psicologia deve se empenhar em contribuir. É necessário que haja uma maior sensibilização em relação à realidade da saúde mental dos idosos, de modo que a produção de conhecimento em relação a essa temática seja ampliada e, possivelmente, convertida em práticas de intervenção.

\section{Relações de Gênero}

Os estudos feministas sobre gênero surgiram nos anos 70 do século XX como estratégias de desconstrução dos lugares sociais desprivilegiados que eram destinados à mulher. Assuntos como o trabalho, a sexualidade, a violência e, posteriormente, a participação política, foram alvo de interesses desses estudos (Figueiredo \& Tyrrel, 2005). A mulher, como primeiro objeto teórico das feministas, foi progressivamente sendo substituída por estudos que contemplassem as diferenças existentes dentro dessa categoria e que abordassem o caráter relacional que o gênero pressupunha. Isto é, criticava-se, sobretudo, o modelo de mulher elitizada que estava sendo adotado, e ressaltava-se a impossibilidade de estudar homens e mulheres separadamente (Scott, 1990). 
Segundo Galinkin, Santos e Zauli-Fellows (2010), a inclusão da abordagem relacional do gênero propiciou a inserção de categorias como raça, classe social, e etnia as quais "dessencializam e desnaturalizam a categoria mulher" (p.22). Como aponta Butler (2010), a distinção sexo/gênero torna-se fictícia e desnecessária ao pensarmos que não há um sexo (natureza) anterior ou fora de uma matriz simbólica cultural. A leitura da diferença anatômica realizada a partir de nossas categorias discursivas (binárias) produz naquilo que é tido como sexo uma desnaturalização. Ou seja, não há um sexo anterior ao discurso que o produz enquanto gênero, mas antes o próprio gênero é performativo "criando" uma diferença sexual (doing gender). Neste sentido, valores e estereótipos relacionados aos sexos são reificados, reafirmados, recriados. Casares (2008) define esses estereótipos como construções sociais, fortemente arraigadas na consciência, constituintes do mundo simbólico e que escapam ao controle da razão.

De acordo com Zanello e Gomes (2010b), em nossa cultura, os valores relacionados às mulheres dizem respeito, sobretudo, à necessidade de renúncia sexual, aos traços de caráter relacionais e ao ideal de beleza/estética; já os valores relacionados aos homens são basicamente dois: virilidade sexual e laboral.

Em relação às mulheres, a renúncia sexual aponta para a necessidade de contenção da sexualidade (renúncia) e o exercício do cuidado com o outro, tais como zelo, abnegação, sinceridade, bondade - traços de caráter relacionais (Bordo 1997; Perrot, 2003; Zanello \& Romero, 2012). A representação maior deste papel seria a naturalização da maternidade (Swain, 2011). Além disso, a mulher deve buscar estar dentro de um padrão estético, marcado, sobretudo, pela lipofobia (Novaes, 2006).

No que se refere aos homens, o ideal de virilidade se firma, de um lado, pelo exercício contundente e ativo de sua sexualidade, mas também pela produtividade laboral (WelzerLang, 2004; Zanello \& Gomes, 2010a). Segundo Azize e Araújo (2003), o relevante na construção da masculinidade é a excelência de desempenho esperada: "não se trata apenas de atingir um padrão viril assumido como dominante, mas de parecer, transparecer, falar, demonstrar esta situação" (p.141). Zanello e Gomes (2010a) apontam que essa dupla virilidade (laboral e sexual) aparece na transposição corriqueira de termos de um âmbito para outro: metáforas relacionadas ao contexto laboral (como "desempenho" e "performance") são utilizadas para fazer referência à virilidade e à potência sexual dos homens. Dessa forma, é possível perceber que, por detrás do discurso que estabelece um modelo de "homem normal", parece haver práticas e características pressupostas que corroboram com a ideia de uma "essência" masculina (Azize \& Araújo, 2003).

Partindo-se da ideia de que nossa cultura privilegia caminhos de subjetivação distintos para "homens" e "mulheres" (Zanello \& Bukowitz, 2011), pesquisar as especificidades dos sentidos subjetivos de ser "velho" e ser "velha" torna-se fundamental para se estudar a saúde mental na velhice, em sua interseccionalidade com gênero. Como aponta Santos (2009), as vivências que parecem estar relacionadas ao nível individual, como as experiências de ser homem e ser mulher, estão ancoradas e moldadas de acordo com certa estrutura social. Assim, se "a velhice marca desigualmente, no juízo social, a mulher e o homem" (Le Breton, 2011, p.56), trata-se então de se perguntar como o envelhecimento coloca em xeque, de forma "gendrada", a saúde mental dos idosos. Há diferenças e especificidades de gênero no sofrimento e no mal-estar de idosos e idosas?

Este trabalho teve como escopo fazer uma análise dos modos como o envelhecimento é vivido por homens e mulheres e sua relação com o sofrimento/saúde mental destes sujeitos. Para tanto, foi escolhida uma instituição geriátrica, tendo em vista ser esta uma das possibilidades sociais disponíveis para o atendimento e cuidado desta população.

\section{Método}

De agosto de 2012 a março de 2013, foram realizadas visitas semanais a uma instituição geriátrica particular de uma capital brasileira, com duração média de 2 horas cada. Foram realizadas 18 entrevistas semi-estruturadas tanto com os idosos como com as idosas ( 9 com homens, 9 com mulheres).

A idade média das mulheres era de 72 anos e a dos homens, 75. Em relação ao nível de escolaridades das 9 mulheres entrevistadas, 3 completaram o ensino fundamental, 4 o ensino médio e apenas uma o ensino superior. Dentre os homens, 5 terminaram o ensino fundamental, 2 o ensino médio e 2 o ensino superior. Cinco idosas recebiam pensão e 3 não; dentre os homens, 7 ganhavam este benefício.

As entrevistas foram realizadas após a assinatura do Termo de Consentimento Livre e Esclarecido. Ou seja, foram contemplados apenas os idosos que não apresentaram nenhum tipo de doença que lhes retirasse o livre exercício da consciência e da vontade. Foram utilizadas algumas questões disparadoras na entrevista, foram elas: Conte-me sua história, o que você fazia antes de vir para cá?; Como é seu contato com as pessoas lá de fora?; O que a palavra "envelhecer" traz à sua cabeça?. As entrevistas foram gravadas e, posteriormente, transcritas. As entrevistas duraram em média 1 hora.

O material obtido foi separado em dois grupos: homens e mulheres. Foi realizada uma análise de conteúdo (Bardin, 1977), através de um levantamento qualitativo de temas e sua classificação em categorias, a partir das falas das idosas e dos idosos. Além da análise qualitativa, foi contabilizada a freqüência das categorias no total das entrevistas, em cada um dos grupos, de mulheres e homens. Além disto, foram comparados os eixos temáticos presentes nas categorias, para saber quais temas eram semelhantes e quais eram específicos de cada um dos grupos; bem como quais valores de gênero apareceram nas respostas colhidas. A presente pesquisa foi aprovada pelo Comitê de Ética do Instituto de Ciências Humanas da Universidade de Brasília.

\section{Resultados e Discussão}

A partir dos dados obtidos nas entrevistas com as idosas e os idosos, foram observadas as seguintes categorias, de acordo com a frequência dentre o total de entrevistas: relações amorosas (M: 100\%; H: 44\%); sexualidade (M: 
89\%; H: 100\%); relação profissional (M: 89\%; H: 78\%); sentido do envelhecer (M: 100\%; H: 89\%); relação com o corpo (M: 89\%; H: 56\%); internação (M: 100\%; H: 89\%), relação com a instituição (M: 100\%; H: 100\%), religiosidade/ espiritualidade (M: 100\%; H: 67\%), relação com a família (M: 100\%; H: 78\%). Apesar de terem sido encontradas as mesmas categorias nas falas das mulheres e dos homens, os sentidos vivenciados nas mesmas, através dos temas, apareceram de forma diferenciada, "gendrada", e com frequências distintas.

As relações amorosas foram mais enfatizadas e recorrentes no discurso das idosas. Para as mulheres, essas relações apareceram marcadas, sobretudo, pela fidelidade e ausência de relações após a morte do marido (78\%), como podemos ver na fala da senhora D: "Eu não quero mais ninguém, não, porque eu não acho que eu vou encontrar mais ninguém que eu vou gostar, não. Meu único era ele mesmo! Muita saudade que a gente sente". A fidelidade e a exclusividade nas relações amorosas não apareceram na fala dos homens. Ao contrário, foi possível perceber poucas falas que se remetiam a um grande amor. Por outro lado, para eles, o tema em questão fez surgir queixas relacionadas à ausência de sexo.

Como destaca Zanello (2014), essa categoria aponta para um caminho privilegiado de subjetivação para as mulheres em nossa cultura: o do dispositivo amoroso (Swain, 2011; Swain, 2012). As mulheres se auto-valorizam e são valorizadas a partir do lugar que ocupam no âmbito das relações amorosas (o casamento que possuem/ terem sido "a escolhida" para alguém), se constituindo e se qualificando narcisicamente a partir do "amor" (Zanello, 2014). Como a temática amorosa apresenta-se dessa forma na vida das mulheres, não é de se estranhar que também apareça como uma das principais formas de sofrimento na velhice, sobretudo em função do grande investimento e/ou decepção, ou da morte daquele no qual o amor foi investido. Além disso, enquanto alguns homens demandavam relações amorosas com o fim de receber cuidados, uma das idosas afirmou indisposição para iniciar um relacionamento, uma vez que este pressuporia ter que se dedicar intensivamente a cuidar do companheiro. Podemos perceber como esse grande investimento nas relações amorosas pelas mulheres também aparece a partir de outro aspecto importante altamente valorizado pela cultura: o investimento no cuidado com o outro enquanto um traço de caráter relacional (Zanello \& Gomes, 2010b).

Enquanto o tema da sexualidade foi hiperenfatizado pelos homens, aparecendo em todas as entrevistas realizadas, as idosas demonstraram muito recato para falar sobre o assunto, tratando-o de forma indireta e sucinta. A temática da sexualidade apareceu no discurso das idosas marcado, essencialmente, por uma ideia de que o sexo só seria possível dentro de uma relação amorosa. Isto aponta para uma especificidade de gênero na nossa cultura: às mulheres é permitido usufruir do desejo sexual, desde que esteja inserida e comprometida com uma vida amorosa. Além disso, nesses discursos, também apareceu a ideia de uma sexualidade satisfatória vivenciada no passado, e inserida na relação com o marido. Diferentemente dos homens, para os quais o sexo, se fosse possível, seria vivenciado no presente e sem a necessidade de um compromisso amoroso. Além disso, apenas uma idosa relatou um grande desprazer sexual vivenciado durante a vida, enquanto outra expôs a ideia de sexo como pecado, a partir de uma ótica religiosa.

Como foi apontado na introdução, em nossa cultura o "verdadeiro" homem seria aquele marcado pela virilidade sexual e laboral (Zanello \& Gomes, 2010a). No caso, isso se mostrou evidente nas entrevistas dos homens (78\%), a partir da afirmação exacerbada de uma excelência de desempenho da virilidade (Azize \& Araújo, 2003). A impossibilidade de exercer a sexualidade na atualidade fez este tema aparecer investido no passado, época em que parece ter havido uma grande realização sexual, como podemos observar a partir da fala do senhor I: "Eu transava por todo canto, eu vendia carro, cada carrão, eu tinha um carrão desses, pegava ele e saia com as meninas, minha mulher ficava doida.". Ou então, a sexualidade apareceu a partir de uma grande insatisfação vivenciada no presente, a ponto de um dos idosos ter oferecido ao entrevistador dinheiro para arrumar uma namorada para ele: "Tô tentando arranjar uma companheira. Uma conservada, sabe? Eu te dou... eu te dou quinhentos. Eu tô com vontade... Ó! Arranja uns sessenta anos pra baixo." (senhor A). Além disso, a sexualidade apareceu em vários momentos: em brincadeiras com a enfermeira ou, também, na expressão de desejo pela entrevistadora.

Pode-se pensar o quanto a velhice, principalmente a partir das representações sociais da sexualidade do velho, coloca em xeque um aspecto identitário desses idosos. Como vimos, não se trata apenas de uma sexualidade prazerosa à qual, muitas vezes, se abdica, mas de um traço identitário que é perdido. É como se, a partir dessa perda crucial de práticas masculinas tidas como "essenciais" (Azize \& Araújo, 2003), o idoso deixasse de ser "homem". Conjuntamente a isso, a vida laboral, que antes estava investida de energia, agora está esvaziada, o que coloca ainda mais em evidência o sofrimento desse idoso que não tem mais onde se constituir identitariamente: "Eu trabalhava, trabalhava e fodia, todo dia. Ah, eu trabalhava muito! Muito, a empresa dava muito trabalho, tinha os funcionários..." (senhor I).

Para quase metade das idosas entrevistadas, a vida profissional foi vivenciada no transcorrer da biografia como algo inconciliável com a vida amorosa. Algumas das idosas entrevistadas relataram ter abandonado o trabalho para agradar o marido: "Por isso que eu não estudei, não. É porque meu marido não deixava. Ele dizia: 'Eu vou ficar sem você, minha filha. Essas moças que muda, na universidade, elas mudam a, a, a, a mente. E eu não quero ficar sem você, só". (senhora G). Para as que conseguiram exercer uma vida laboral, o trabalho também se mostrou satisfatório. No entanto, a relação com o trabalho, para essas mulheres, se mostrou diferente da dos homens, que consideraram o trabalho como ponto fundamental. No caso deles, houve um grande investimento na vida profissional no decorrer da vida, a ponto de um dos idosos ter relatado ter vivenciado um "casamento" com o trabalho. Nesse caso, o emprego atuou, anteriormente, como fator de proteção para a saúde mental do idoso, uma vez que o trabalho no âmbito público é visto como posto de reconhecimento. Por outro lado, tornou-se, na velhice, um fator de risco para o senhor $\mathrm{C}$, pois, por não ter investido nas relações familiares, e por não possuir mais 
a companhia dos amigos, o idoso se vê atualmente em uma ausência de relações externas.

Também foi possível perceber esse investimento na esfera pública laboral a partir das relações que os homens continuaram a manter (mesmo depois da internação geriátrica) com os colegas de trabalho. Diferentemente das mulheres, as quais mostraram manter nas relações familiares seus laços mais fortes (público que mais as visitava). Isso também influenciou o modo de vivenciar a internação: já que para estas mulheres o principal investimento ao longo da vida foi o familiar, a internação foi ressentida e relatada com um sofrimento muito mais intenso, visto que apostaram tanto nessas relações. Apesar disso, alguns homens mostraram sentimentos dolorosos de culpa e arrependimento em relação a essa falta de investimento na família, como podemos ver na seguinte fala do senhor C: "Ah, ooo fiz tudo separado da minha família, ai, não sei, tive 12 filhos...". Entrevistador: "Mas o senhor pensa que algo poderia ser melhor hoje?" "Não, se eu pudesse escolher, eu mais cedo viesse o que não veio que é o amor, isso ai traz alegria pra gente. Aqui eu sinto o que eu não sentia, né, amor, o amor que eu tinha era pouco, e eu não me dediquei, troquei por amizades, outros que estão lá também, eu bebia, jogava, era só diversão.".

O sofrimento da internação também se mostrou muito mais racionalizado dentre os homens. Neste sentido, os homens deram como motivações para a internação o tratamento de problemas físicos de saúde, os quais poderiam ter sido atendidos a partir de outros serviços que não na instituição geriátrica. Pode-se também pensar como esse mecanismo de defesa é muito mais utilizado entre eles do que entre elas: no caso das mulheres apareceu muito mais a negação e o silenciamento do sofrimento, reforçando, na maioria das vezes, uma posição de "auto sacrifício" frente ao asilamento. Isto é, apesar de não quererem morar na instituição geriátrica, elas viraram reféns do desejo dos familiares em troca de manter o amor que deles recebiam, como ilustra a fala a seguir da senhora R. Entrevistadora: "A senhora gostou de vir pra cá?" "Não, gostar eu não gostei. Mas vendo a situação dela em casa, aceitei, né? É uma maneira de ajudá-la, né? Aceitei.".

Essa posição de silenciamento como moeda de troca para ser amada pôde também ser encontrada diante da grande decepção amorosa sofrida, como podemos ver na fala da senhora $\mathrm{C}$ :

"Era bonito, mas aí me maltratou demais da conta, mas judiou (referindo-se a uma traição amorosa) demais de mim (...). Eu não quero ver ele, não. Não quero não. Saber o que ele fez e... Não poder falar nada de nada. Porque ele não deixou que eu soubesse de nada. Era difícil demais. Não quero saber de homem de jeito nenhum. Mas eu fiquei muito doente, fiquei derrubada depois disso, sabe? Fiquei triste demais... Falava com as filhas dele, assim, mas não contava pra ninguém. Nunca contei isso pra ninguém. (...) Eu não quero ver ele não. Não quero não. Saber o que ele fez e... Não poder falar nada de nada.".

Como podemos observar, unido ao sofrimento de ter sido traída, há outro: além da dor que o marido lhe perpetrou, há a dor de não poder compartilhar a traição sofrida com ninguém, devendo a idosa permanecer silenciada. No decorrer da entrevista, a idosa afirmou que, ao tentar falar com uma de suas filhas sobre a traição sofrida, a filha lhe ofereceu dinheiro e a encaminhou para uma psicóloga, pois esta sim "saberia o que fazer". Havia, portanto, um duplo sofrimento: da traição e do silêncio desta. Ao contrário dos homens que, culturalmente, têm uma permissão maior para exporem seus descontentamentos, o lugar social destinado às mulheres em relação ao sofrimento parece ser de resignação e silêncio (Garcia, 1995).

Este silenciamento também apareceu na expressão das insatisfações presentes na relação com a instituição geriátrica, que só se manifestaram ou foram reveladas de forma bastante indireta, emergindo com negação ou ambivalência: " $E u$ to muito bem, eu to satisfeita. E não tem nada o que pagar, não tem conta, não tem nada o que pagar, sabe? Tá tudo bem. To satisfeita. É muito bom (...). Muitas coisas que eu vejo que sei que elas (as enfermeiras) tiram de mim também." Entrevistadora: "Das suas coisas?" "Das minhas coisas normais. Elas tiram, aqui nesse caso. Eu vou deixando, eu não quero falar, que se eu falar vai ser pior. Então fica nisso mesmo, felizmente. Eu to muito bem, eu to satisfeita. E não tem nada o que pagar, não tem conta, não tem nada o que pagar, sabe?" (senhora N). Já as insatisfações vivenciadas pelos homens idosos, na instituição, parecem ser muito mais ativas, explícitas, e diretamente nomeadas, como expõem o senhor D e o senhor N: "Mingau véi ruim. Quero isso não, sem gosto, sem nada, e eles colocam um pozinho." (senhor D).

"Eu acho que se você for ali, parece que sacudiram um galho de velho e as folhas cairam no chão. Tá tudo lá no sol, isso porque... porque os pais... os filhos da puta, não querem mais os pais em casa e jogam lá, botam ele pra lá, por isso aqui chama Lar dos Velhinhos (nome fictício), aqui é o Lar dos Velhinhos! O deles não é mais! Botam os velhinhos aí, botam uma cama pra eles dormir, e acha que isso é o suficiente." (senhor N).

No entanto, se os homens nomeiam e dizem em alto tom seu sofrimento e mal estar, enquanto as mulheres manifestam o sofrimento, sobretudo, de forma indireta, elas acabam se beneficiando desse silenciamento, uma vez que, ao não impor seu desejo e evitar reclamar, conservam o "carinho" recebido pelos profissionais da instituição, configurando-se em um ganho secundário: "Sou bem tratada aqui graças a Deus... Aqui eu sou respeitada, bem tratada, mas a gente tem que fazer o que eles querem, né? Tem que fazer o que eles querem e não aquilo que a gente gosta." (senhora F).

Dentro da relação com a instituição, por outro lado, pareceu ser muito mais permitido às mulheres exercerem sua subjetividade usufruindo de tarefas de lazer e satisfação, como: costurar, cuidar do corpo (manicure, cabeleireira), e participar de atividades religiosas, estando o ócio mais presente na queixa dos homens. O cuidado com o corpo foi vivenciado de maneira específica e "gendrada" pelas mulheres, pois a este cuidado estava vinculada uma vaidade com questões estéticas, enquanto que para os homens pareceu ser muito mais permitido esse abandono com a aparência, estando o cuidado restrito a questões básicas de saúde e/ou de higiene. Com isso, podemos pensar que a experiência de estar num corpo fora dos padrões estéticos de beleza e juventude socialmente valorizados é propiciador de um sofrimento e de uma insatisfação muito maior para as idosas, como podemos ver no seguinte trecho do discurso da senhora J: 
"Porque, olha, não sei se, porque quando eu tinha 13 anos, eu era, nem me lembro quando eu tinha 13 anos, eu era magrinha dessa grossura. É, bem magrinha, finiiinha. Agora não, eu tenho 84, não sei se é a idade que deforma. Sobe os 'quadrilho'. E eu tenho desvio de coluna. Acho que sobe os 'quadrilho', hein. Porque, porque eu sou horrivel, 'sinhá'. Ninguém quer simpatizar comigo, hein. Eu não tenho nada. Não tem pessoas que é feia, mas é atraente? Atraente assim... que atrai qualquer homem, hein, rapaz. Nunca achei, não. Gosto assim, vestir... ter uma boa aparência, gosto muito de aparência".

A maioria das idosas coloca a religião em um lugar privilegiado em suas vidas (78\%), contrapondo-se à maioria dos idosos que não deram muita relevância para a prática da fé $(83 \%)$. No entanto, apesar de a religião surgir como uma possibilidade de funcionar como um fator de proteção à saúde mental na vida dessas mulheres, a maioria delas afirmou possuir sentimentos de vulnerabilidade e resignação frente à proximidade da morte $(67 \%)$. Metade dos homens entrevistados significou o envelhecimento da mesma forma, entretanto o mesmo número de idosos considerou o sentido do envelhecer sob a ótica de perdas e degeneração físicas, incluindo a impotência sexual, relatada por um deles. Dentre as falas das idosas que englobaram o tema da religiosidade e colocaram-na em um lugar decisivo, foi possível perceber que, por meio da reza, as relações familiares são, novamente, o foco de investimento dessas mulheres.

A categoria "relações familiares" se refere às relações dos idosos e das idosas antes, durante ou depois do internamento, e a como são vivenciadas essas relações atualmente. $\mathrm{O}$ abandono foi o tema mais presente nas entrevistas das mulheres, emergindo a partir de um grande sofrimento e ressentimento (44\%). Em relação aos homens, o abandono, apesar de ter sido também o tema mais relatado (72\%), surgiu camuflado a partir do mecanismo da racionalização:

"Sim, visitam, mas meus filhos têm mais o que fazer, né. Moram no Guará, tenho dois menino, homem já, tem suas familias, sua esposas, meus netos, tem trabalho, ir no supermercado, levar pra creche, eu quero é que eles vivam a vida deles, eles visitam de vez em quando." (senhor $\mathrm{D})$.

Talvez se colocar em uma posição de vulnerabilidade e fragilidade seja uma dificuldade patente para os homens, uma vez que rompe de forma brutal com o ideal de masculinidade e virilidade demandado socialmente. Além disso, as falas sobre a família foram desenvolvidas de forma muito mais espontânea e fluida pelas idosas, enquanto que os idosos faziam considerações escassas e pontuais.

\section{Conclusão}

A compreensão do sofrimento psíquico de idosas e de idosos institucionalizados perpassa o entendimento de como os sujeitos são constituídos socialmente, e como são subjetivados os valores e relações de gênero. Como podemos perceber, os dados apontam para um sofrimento gendrado da velhice na instituição geriátrica.

A partir da categoria das relações amorosas foi percebido um grande investimento e importância em relações fiéis e monogâmicas na vida das mulheres. Para elas, a sexualidade tem como pré-requisito o amor. Ao contrário, para os homens, as relações amorosas não aparecem de forma espontânea em suas falas. Além disso, essa categoria foi evidenciada a partir de outros temas que não o da fidelidade, como o sexo e a exaltação da virilidade sexual.

Enquanto para a maioria das idosas, as relações profissionais foram postas em segundo plano no decorrer da vida, para os idosos a atividade produtiva representou uma peça fundamental em seu funcionamento identitário de "ser homem". A velhice, portanto, parece ter colocado em xeque esta identidade. Para aqueles idosos que no passado se ancoravam, sobretudo, nas relações com os amigos de trabalho, a perda desses vínculos, em consonância com a ausência de investimento nos elos familiares, acabou atuando como um fator desencadeador de processos de luto.

A família, enquanto objeto socialmente privilegiado de investimento das mulheres no decorrer da vida, tornase, com o abandono promovido pela internação, motivo de maior ressentimento, mais evidente dentre elas do que entre eles. Os sentimentos encontrados nos idosos, ao contrário, se envergam em um arrependimento por não terem valorizado as relações familiares no passado, e ainda a partir de mecanismos que servem à proteção contra essa fragilidade afetiva.

Além disso, o sentido do envelhecer põe em evidência o modo como o corpo é tomado de forma diferenciada pelas idosas e pelos idosos. Apesar de ambos, em sua maioria, relacionarem a vivência corporal na velhice com perdas e degenerações, a imagem e o cuidado corporal para a idosa se aproxima mais de uma valorização com a aparência. Para elas a ênfase recai mais a uma estética que hoje as exclui de um modelo de juventude e beleza, enquanto que para os idosos, a atenção com o corpo se vincula a motivações triviais de cuidados básicos.

O gênero se apresenta como um fator transversal configurador de importantes diferenças e especificidades de sofrimento psíquico. Dessa forma, faz-se imprescindível levar em consideração os valores de gênero na formulação de políticas públicas de saúde mental para idosos. Neste sentido, questiona-se a ausência e falta de iniciativa em construir oficinas terapêuticas que levem em consideração essa dimensão na instituição geriátrica. Experiências de intervenções em saúde mental utilizando gênero já foram realizadas e tiverem boa eficácia terapêutica (Zanello \& Souza, 2009). A maioria das idosas fez referência a atividades que poderiam ser instituídas a partir de oficinas organizadas pela instituição geriátrica, como oficinas de cozinha, costura e leitura. Também se faz necessário pensar e efetivar ações que promovam possibilidades de lazer para os idosos que tanto se queixaram do ócio na instituição. Esses programas poderiam funcionar como fatores de proteção da saúde mental colocando o gênero a serviço da vida dos idosos e das idosas, além de resgatar e resguardar suas subjetividades frente à estruturação genérica da instituição geriátrica. 


\section{Referências}

Angold, A. \& Heim, C. M. (2008). Perspectiva de Desenvolvimento com Foco em Trauma Infantil. In Narrow, W. E., First, M. B., Sirovatka, M. S. \& Regier, D. A. (orgs.). Gênero e Idade: considerações no diagnóstico psiquiátrico. 79-98. São Paulo: ROCA.

Azize, R. L. \& Araújo, E. S. (2003). A pílula azul: Uma análise de representações sobre masculinidade em face do Viagra. Antropolítica (14), 133-151. Acedido em Abril 7, 2012, em http://www.uff.br/antropolitica/revistasantropoliticas/ revista_antropolitica_14.pdf

Bardin, L. (1977). Análise de Conteúdo. Lisboa, Portugal: Edições 70.

Bordo, S. (1997). O corpo e a reprodução da feminidade: uma apropriação feminista de Foucault. In: A. M. Jaggar \& S. R. Bordo (orgs). Gênero, corpo, conhecimento. Rio de Janeiro: Record/ Rosa dos temos, 19-41.

Butler, J. (2010). Problemas de gênero: feminismo e subversão da identidade. Rio de Janeiro: Civilização Brasileira.

Cachioni, M. (2003). Quem educa os idosos? Um estudo sobre professores de universidades da terceira idade. ( $1^{\mathrm{a}}$ edição). Campinas: Alínea.

Campos, A. P. M. (2005). “Tricotando Histórias": reflexões sobre uma intervenção psicológica grupal com idosas. (Unpublished master's thesis), Universidade de Brasília, Brasil.

Carvalho, J. A. M. \& Garcia, R. A. (2003). O envelhecimento da população brasileira: um enfoque demográfico. Cadernos de Saúde Pública, 19(3), 725-733. Acedido em Abril 5, 2012, em http://www.scielo.br/scielo.php?script=sci_ arttext\&pid=S0102-311X2003000300005\&lang=pt

Carvalho, M. I. L. B. (2009). Os cuidados familiares prestados às pessoas idosas em situação de dependência: características do apoio informal familiar em Portugal. Revista Kairós, 12(1), 77-96. Acedido em Abril 4, 2012, em http://revistas.pucsp. br/index.php/kairos/article/viewFile/2781/1816

Casares, A. M. (2008). Antropologia del gênero: cultura, mitos e estereótipos sexuales. Madri: Cátedra.

Falcão, D. V. S. \& Carvalho, I. S. (2010). Idosos, gênero e saúde mental. In D. V. S. Falcão \& L. F. Araújo (orgs). Idosos e Saúde Mental. Campinas: Papirus.

Fernandes, M. G. M. (2009). Problematizando o corpo e a sexualidade de mulheres idosas: o olhar de gênero e geração. Revista de enfermagem UERJ, 17(3), 418-422. Acedido em Abril 5, 2012, em http://www.facenf.uerj.br/v17n3/v17n3a21. pdf

Figueiredo, M. L. F. \& Tyrrel, M. A. R. (2005). O gênero (in) visível da terceira idade no saber da enfermagem. Revista Brasileira de Enfermagem, 58(3). 330-334. Acedido em Abril 4, 2012, em http:/www.scielo.br/scielo.php?script=sci arttext\&pid=S0034-71672005000300015\&lang=pt\&tlng=

Garcia, C. C. (1995). Ovelhas na névoa: um estudo sobre as mulheres e a loucura. Rio de Janeiro: Rosa dos tempos.

Galinkin, A. L., Santos, C. \& Zauli-Fellows, A. (2010). Estudos de Gênero na Psicologia Social. In A. L. Galinkin \& C. Santos (orgs). Gênero e psicologia social: interfaces. Brasília: Technopolitik.

Gonçalves, I. F. (2001). Mulheres idosas e qualidade de vida: um estudo do grupo de convivência do noeti/ufmt. (Unpublished master's thesis) Universidade de Brasília, Brasília, Brasil.
Le Breton, D. (2011). O envelhecimento intolerável. In: Antropologia do Corpo e Modernidade. Petrópolis: Vozes.

Lopes, R. G. C. (2000). Saúde na velhice: as interpretações sociais e os reflexos no uso do medicamento. São Paulo: EDUC.

Moraes, A. (2011). O corpo no tempo: velhos e envelhecimento. In: M. Del Priore \& M. Amantino. História do corpo no Brasil. São Paulo: Unesp.

Neri, A. L. (1995). Psicologia do envelhecimento: uma área emergente. In A. L. Neri (org). Psicologia do Envelhecimento, 13-40. Campinas: Papirus.

Neri, A. L. (2004). O que a psicologia pode oferecer ao estudo e à intervenção no campo do envelhecimento no Brasil, hoje. Revista Brasileira de Ciências do Envelhecimento Humano, 1(1), 69-80. Acedido em Abril 5, 2012, em http://www.upf.br/ seer/index.php/rbceh/article/view/46/55

Neri, A. L., \& Freire, S. A. (orgs.). (2000). E por falar em boa velhice. Campinas: Papirus.

Novaes, J. V. (2006). O intolerável peso da feiura: sobre as mulheres e seus corpos. Rio de Janeiro: Ed. PUC-Rio/Garamond.

Pereira, E. T. (2009). A terceira idade na universidade aberta: navegando, buscando, aprendendo em um mar sem fim. (Unpublished doctor dissertation), Pontifícia Universidade Católica de São Paulo, São Paulo, SP, Brasil.

Perrot, M. (2003). Os silêncios do corpo da mulher. In: M. I. S. Matos \& R. Soihet (org). O corpo feminino em debate. São Paulo: UNESP, 13-27.

Santos, A. M. C. C. (2009). Articular saúde mental e relações de gênero: Dar voz aos sujeitos silenciados. Ciência \& Saúde Coletiva, 14(4), 1177-1182. Acedido em Abril 5, 2012 em http://www.scielosp.org/scielo.php?script=sci_arttext\&pid $=$ S1413-81232009000400023

Scott, J. (1990). Gênero: uma categoria útil para análise histórica. Educação e Realidade. 15(2), 22. Acedido em Abril 4, 2012, em http://www.dhnet.org.br/direitos/textos/generodh/ gen_categoria.html

Souza, A. C. C. (2006). Avaliação do grau de independência de moradores de uma instituição de longa permanência para idosos. (Unpublished master's thesis). Convênio Rede Centro Oeste - UnB, UFG, UFMS, Goiânia, GO, Brasil.

Swain, T. N. (2011, agosto). Diferença sexual: uma questão de poder. Texto apresentado no I Simpósio de Gênero e Literatura da Universidade Federal do Ceará, Brasil. Acedido em Agosto 18, 2012, em http:/www.tanianavarroswain.com.br/brasil/ diferenca $\% 20$ sexual.htm

Swain, T. N. (2012, inédito). La construction des femmes : le renouveau du patriarcat (Texto inédito apresetando em Lausanne, França).

UNFPA, \& HelpAge (2012). Envelhecimento no Século XXI: Celebração e Desafio (resumo executivo).

Vieira, M. G. O. (2009). Velhice e espiritualidade: reflexões sobre as transformações do envelhecer. (Unpublished master's thesis) Universidade de Brasília, Brasil.

Vieira, K. F. L., Miranda, R. S. \& Coutinho, M. P. L. (2012). Sexualidade na velhice: Um estudo de representações sociais. Psicologia e Saber Social, 1(1), 120-128.

Welzer-Lang, D. (2004). Les hommes et Le masculin. Paris: Payot. Zanello, V. (2014). Saúde mental, gênero e conjugalidade. In: Stevens, C.; Oliveira, S. \& Zanello, V. (Org). Estudos Feministas e de Gênero: Articulações e Perspectivas. Florianópolis: Ed. Mulheres. 
Zanello, V. \& Bukowitz, B. (2011). Loucura e cultura: Uma escuta das relações de gênero nas falas de pacientes psiquiatrizados. Revista Labrys Estudos Feministas. Acedido em Abril 4, 2012, em http:/www.tanianavarroswain.com.br/labrys/labrys20/ bresil/valeska.htm

Zanello, V. \& Gomes, T. (2010a). Xingamentos masculinos: A falência da virilidade e da produtividade. Caderno Espaço Feminino (UFU), 23(1/2), 265-280. Acedido em Abril 5, 2012, em http://www.seer.ufu.br/index.php/neguem/article/ view/7615/7079
Zanello, V. \& Gomes, T. (2010b) Xingamentos: sintoma e reprodução da sociedade patriarcal. In: Magalhães, M.J.; Tavares, M.; Coelho, S.; Góis, M. \& Seixas, E.. (Org.). Quem tem medo dos feminismos?. Lisboa: Nova Delphi, 333-338.

Zanello, V. \& Romero, A.C. (2012). "Vagabundo" ou "vagabunda": Xingamentos e relações de gênero. Revista Labrys Estudos Feministas. Acedido em Agosto 20, 2013, em http://www. tanianavarroswain.com.br/labrys/labrys22/libre/valeskapt.htm

Zanello, V. \& Souza, G. J. O. (2009). Mais música menos haldol: Uma experiência entre música, phármakon e loucura. Mental 7(13). Acedido em Abril 4, 2012 em http://pepsic. bvsalud.org/scielo.php?script=sci_arttext\&pid=S167944272009000200009\&lng=pt\&nrm=iso\&tlng=pt

Recebido em 22.03.2014

Primeira decisão editorial em 10.11.2014

Versão final em 08.01.2015

Aceito em 28.10.2015 